(C) 2017, THE AUTHORS. Published by FASS and Elsevier Inc. on behalf of the American Dairy Science Association ${ }^{\circledR}$.

This is an open access article under the CC BY-NC-ND license (http://creativecommons.org/licenses/by-nc-nd/3.0/).

\title{
Bivariate threshold models for genetic evaluation of susceptibility to and ability to recover from mastitis in Danish Holstein cows
}

\author{
B. G. Welderufael, ${ }^{*} \dagger^{1}$ L. L. G. Janss, $\dagger$ D. J. de Koning, ${ }^{*}$ L. P. Sørensen, $†$ P. Løvendahl, $†$ and W. F. Fikse* \\ *Department of Animal Breeding and Genetics, Swedish University of Agricultural Sciences, Box 7023, SE-750 07 Uppsala, Sweden \\ †Center for Quantitative Genetics and Genomics, Department of Molecular Biology and Genetics, Aarhus University, Blichers Allé 20, PO Box 50, \\ DK-8830 Tjele, Denmark
}

\section{ABSTRACT}

Mastitis in dairy cows is an unavoidable problem and genetic variation in recovery from mastitis, in addition to susceptibility, is therefore of interest. Genetic parameters for susceptibility to and recovery from mastitis were estimated for Danish Holstein-Friesian cows using data from automatic milking systems equipped with online somatic cell count measuring units. The somatic cell count measurements were converted to elevated mastitis risk, a continuous variable [on a $(0-1)$ scale] indicating the risk of mastitis. Risk values $>0.6$ were assumed to indicate that a cow had mastitis. For each cow and lactation, the sequence of health states (mastitic or healthy) was converted to a weekly transition: 0 if the cow stayed within the same state and 1 if the cow changed state. The result was 2 series of transitions: one for healthy to diseased (HD, to model mastitis susceptibility) and the other for diseased to healthy (DH, to model recovery ability). The 2 series of transitions were analyzed with bivariate threshold models, including several systematic effects and a function of time. The model included effects of herd, parity, herd-test-week, permanent environment (to account for the repetitive nature of transition records from a cow) plus two time-varying effects (lactation stage and time within episode). In early lactation, there was an increased risk of getting mastitis but the risk remained stable afterwards. Mean recovery rate was $45 \%$ per lactation. Heritabilities were 0.07 [posterior mean of standard deviations $(\mathrm{PSD})=0.03]$ for $\mathrm{HD}$ and 0.08 $(\mathrm{PSD}=0.03)$ for $\mathrm{DH}$. The genetic correlation between $\mathrm{HD}$ and $\mathrm{DH}$ has a posterior mean of -0.83 (PSD $=$ $0.13)$. Although susceptibility and recovery from mastitis are strongly negatively correlated, recovery can be considered as a new trait for selection.

Key words: bivariate model, dairy cow, recovery ability, susceptibility to mastitis

Received August 19, 2016.

Accepted March 1, 2017.

${ }^{1}$ Corresponding author: berihu.welderufael@slu.se

\section{INTRODUCTION}

Dairy cow mastitis is a typical and frequent disease causing large economic losses and problems in milk quality and dairy products worldwide (Halasa et al., 2007; Hogeveen et al., 2011). Most genetic evaluations of mastitis are performed based on either the analyses of recorded treatments of clinical mastitis (CM) or measurements of SCC. Recent studies show that off-farm CM records can be used in routine genetic evaluations (Jamrozik et al., 2013; Govignon-Gion et al., 2016). The assumption is that selection would be more efficient if genetic evaluations were performed on occurrences of mastitis. However, such routine recording of occurrences of CM at the farm or cow level is not easily available in many countries because of difficulties in detection of CM (Carlén et al., 2006). On the other hand, the technological advances in farming and especially automatic milking systems (AMS) have made SCC records easily accessible on a large scale and at almost no cost (e.g., through the online cell counter fitted in the AMS). At present, SCC or logtransformed SCC (SCS) values are therefore used as the major phenotypic measure in genetic evaluations to improve udder health (Sørensen et al., 2009). The use of SCC in genetic evaluations of dairy cattle has a long history. In the United States during the late 1970s and early 1980s, dairy herd breeding programs began to implement SCC measurements for assessment of mastitis cases (Shook and Schutz, 1994). Such historical and wide acceptance of SCC as a proxy for mastitis is due to its ease of recording and high genetic correlation with mastitis (Emanuelson et al., 1988; Gernand and Konig, 2014).

Often, mastitis is seen as a categorical or binary trait, reflecting the presence or absence of mastitis within a defined time interval (Vazquez et al., 2012). In genetic evaluations, this all-or-none trait definition may not fully utilize all information available in the data; for instance, the time that it takes to recover or different levels of infection (Carlén et al., 2005; Vazquez et al., 2009). Højsgaard and Friggens (2010) introduced the 
concept of "degree of infection" to define a cow's health status on a continuous scale where low values indicate healthy cows and high values indicate mastitic cows. A more recent concept, elevated mastitis risk, was introduced by Sørensen et al. (2016). Elevated mastitis risk (EMR) evaluates a cow for the risk of having contracted mastitis based on online SCC (OCC) recorded with an AMS. Online and inline sensor systems installed in the AMS (DeLaval International AB, Tumba, Sweden) are equipped with a cell counter from which OCC measures can easily be read and automatically recorded on a regular basis.

In current genetic evaluations, only susceptibility to mastitis is taken into account. In this study, we wanted to include the recovery process in the analysis. A method developed by Franzén et al. (2012) included both the disease susceptibility and the recovery process by modeling transitions to and from states of infection in a univariate analyses. More recently, Welderufael et al. (2017) developed a bivariate threshold sire model for joint estimation of breeding values for susceptibility to and recovery from mastitis based on changes in SCC. These methods and models enable us to include both directions of a disease susceptibility to and recovery from mastitis - in the analysis. This enhances the genetic evaluation of mastitis by the ability to capture genetic variation not only for susceptibility to, but also for recovery from, mastitis. However, those studies (Franzén et al., 2012; Welderufael et al., 2017) were based on simulated data. In this study, we applied these models for the first time to real data. We analyzed real data obtained from Danish research and commercial dairy herds of Holstein-Friesian cows, each using AMS fitted with OCC measuring units. The objectives were, therefore, (1) to evaluate whether the model developed by Franzén et al. (2012) and Welderufael et al. (2017) is identifiable and can be fitted to real data, and (2) to estimate genetic parameters of mastitis susceptibility and recovery ability for Danish Holstein cows using bivariate threshold models.

\section{MATERIALS AND METHODS}

\section{Data}

Data were extracted from a database connected to VMS milking robots (Voluntary Milking System, DeLaval International AB) fitted with OCC measuring units. The data contained 2,903,447 milking records for milk yield, OCC, and electrical conductivity of milk from 3,193 cows, from April 1, 2008, to October 31, 2012, from one research herd (Danish Cattle Research Center, Tjele, Denmark) and 6 commercial dairy herds. The data were composed of different breeds (Danish
Holstein, Danish Red Holstein, Danish Jersey, Red dairy cattle, and a few cows of unknown breed). Part of the data from the Research Center (387 cows from 2 groups of Danish Holstein and 1 group of Danish Jersey), consisting of 150,468 milking records, were used by Sørensen et al. (2016) to develop a mastitis detection model.

Because individuals with an unknown sire are not very informative (especially in a sire model), they were filtered out. Only cows from sires with 5 or more daughters were kept. Because the data included relatively few Danish Jersey and Red dairy cattle, cows belonging to these breeds and cows of unknown breed were excluded, and 1,791 Danish Holstein cows were used for the final analyses. The data were further restricted to include only parities 1 to 3 , and only the first $365 \mathrm{~d}$ of lactation. Table 1 shows the number of records, sires, and cows by herd for the edited data used in the final analyses. For cows changing herds during the lactation, only the records from the first herd were kept.

\section{Converting OCC to EMR}

The OCC were converted to EMR values according to the procedure outlined by Sørensen et al. (2016). In brief, raw OCC values were checked for validity and then log-transformed to reduce the skewness of the distribution, followed by a single exponential smoothing at sensor level performed to minimize errors caused by instruments. Next, the level and trend in OCC values were determined by fitting a time-series model at cow level, using a double exponential smoothing. The level and trend were combined into a latent using factor analysis, followed by a sigmoid transformation to convert the latent indicator variable to a continuous $[0 ; 1]$ scale. This indicator, referred to as EMR, predicts the risk of a cow having mastitis: values close to 0 indicate

Table 1. Number of transition records, sires, and cows by herd

\begin{tabular}{lrrr}
\hline Herd $^{1}$ & Sires & Cows & Records $^{2}$ \\
\hline 1 & 45 & 134 & 9,848 \\
2 & 68 & 388 & 13,039 \\
3 & 68 & 270 & 11,102 \\
4 & 45 & 233 & 7,006 \\
5 & 61 & 346 & 14,896 \\
6 & 52 & 224 & 15,569 \\
7 & 43 & 302 & 17,772 \\
Total & 382 & 1,897 & 89,232 \\
\hline
\end{tabular}

${ }^{1}$ The first 6 herds were commercial farms; herd 7 was a research herd. ${ }^{2}$ Records were made for weekly transitions between assumed states of mastitis and non-mastitis: 0 if the cow stayed within the same state during the whole week, and 1 if the cow changed state. For cows changing herds during the lactation, only the records from the first herd were kept. 
a low risk of mastitis and values close to 1 indicate a high risk of mastitis.

\section{Converting EMR to State Transitions}

The EMR values were used to determine whether a cow was healthy: EMR values above a certain threshold $(\mathrm{EMR}=0.6)$ were assumed to indicate that the cow had mastitis (Figure 1). If there were multiple observations per day, the highest EMR value was used to create a sequence of transitions. Multiple records of elevated cell counts (EMR values above the threshold) within 7 consecutive days for an individual cow were assumed to describe the same case, and health status for all days was set to mastitic. To test the robustness of our model, we also repeated part of the analyses using an EMR threshold of 0.8.

Next, for each cow and lactation, the sequence of health states (healthy or diseased) was converted to weekly state transitions: 0 if the cow stayed within the same state during the whole week, and 1 if the cow changed state. Following the procedure and model developed by Franzén et al. (2012), 2 series of transitions were created: one for healthy to diseased (HD), to model mastitis susceptibility, and the other for diseased to healthy (DH), to model recovery ability. Transitions were determined for weekly intervals to keep the size of the data manageable. To determine the sequence, the highest EMR values were used as starting values. A time variable was added to indicate the length of each episode. An episode is defined as the duration of each state; after a transition, a new episode begins, leading to multiple episodes within lactation (Franzén et al., 2012). The time indicator counted the weekly intervals until a transition occurred. Because only a few cows had high OCC for a long time, there were very few data points for $\mathrm{DH}$ in combination with long episodes. The time indicator was therefore log-transformed to avoid substantial influence of these data points in the analyses.

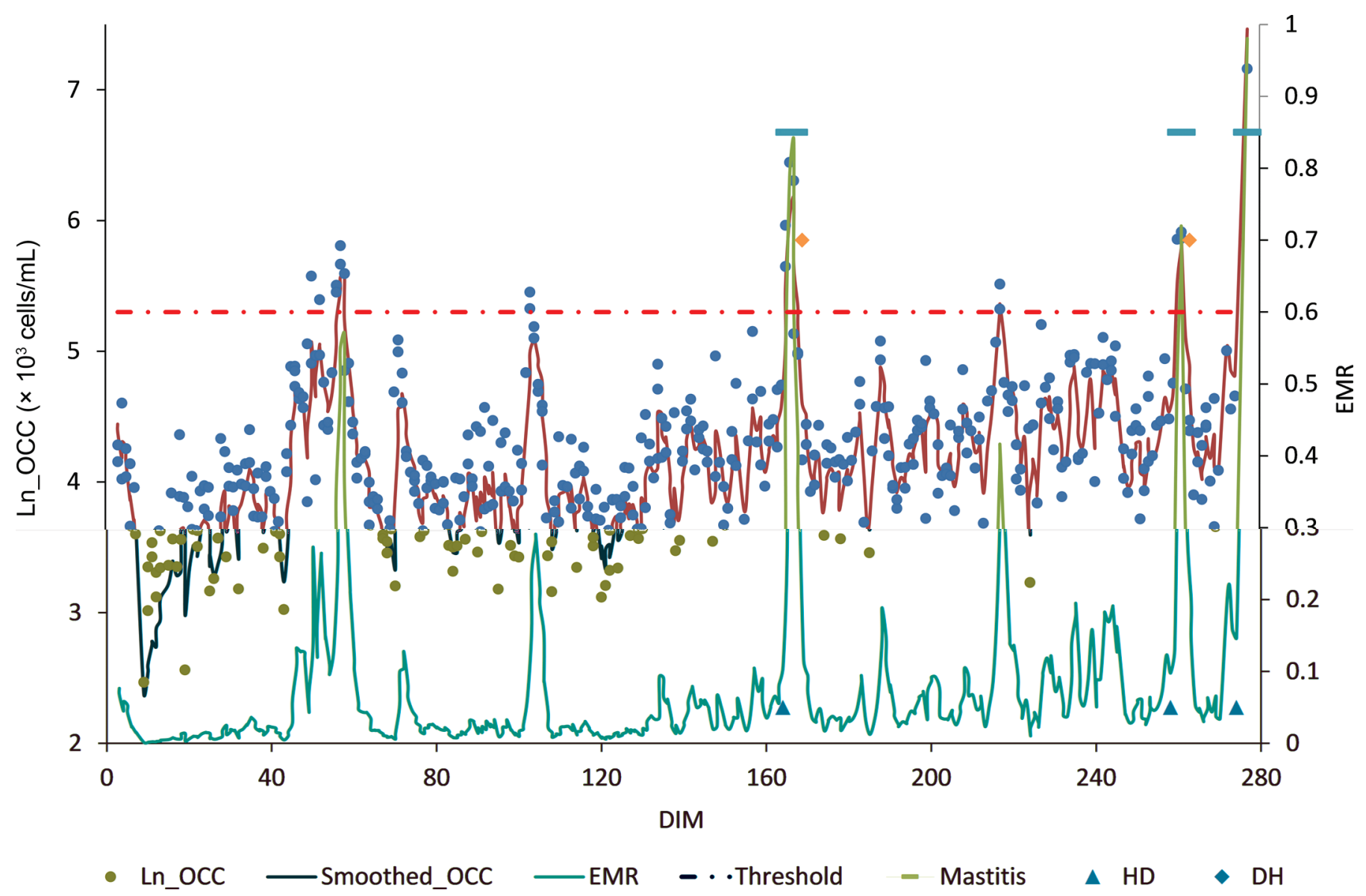

Figure 1. Data modeling from online SCC (OCC) to transitions for a single cow. The OCC (Ln_OCC) from every milking of a cow were smoothed (Smoothed_OCC) and converted into a mastitis risk indicator variable, EMR. From the sequence of EMR-based health states ("mastitis" if EMR >0.6), 2 series of transitions were created: one for healthy to diseased (HD) to model susceptibility to mastitis and the other for diseased to healthy (DH) to model recovery from mastitis. Color version available online. 


\section{Analysis of Transitions}

The observed transitions were analyzed with a threshold sire model and a threshold animal model, assuming the binary transition data were the outcome of an unobserved underlying normally distributed continuous scale called liability (Gianola and Foulley, 1983). Accordingly, observed transitions (y) were linked to the underling liability $(\lambda)$, such that the observed binary response takes a value of 1 if $\lambda$ was larger than a fixed threshold $(\tau)$, and 0 otherwise. Formally, this can be presented as follows:

$$
\mathrm{y}= \begin{cases}1, & \text { if } \lambda>\tau \\ 0, & \text { if } \lambda \leq \tau\end{cases}
$$

In threshold models for binary data, the threshold $(\tau)$ and mean on the liability scale are not identifiable, and usually the threshold is set to an arbitrary value: $\tau=0$, such that $y=1$ if $\tau>0$ and 0 otherwise, and the mean on the liability scale models the average probability for $\mathrm{y}=1$.

The observed transitions were modeled as a linear combination of systematic effects and of a function of time. A lactation curve $[\mathrm{f}(\mathrm{DIM})]$ was modeled by a combination of Legendre polynomials and a Wilmink term $\left(\exp ^{-0.05 \times D I M}\right)$ (Wilmink, 1987), to reflect the fact that susceptibility and recovery are not constant during the lactation. For example, de Haas et al. (2002) and Nyman et al. (2007) reported that most mastitis cases occur in the first part of lactation. Changes of risk during each episode $[\mathrm{f}($ time $)]$ were modeled with Legendre polynomials. This time effect reflects that the recovery rate during the first week after getting infected may be different from the recovery rate in, for example, the third week after infection, and that a healthy cow may have different risk in the first week after recovery from a previous episode compared with a cow that has been healthy for many weeks. Deviance information criteria were used to compare different models and regression functions (see supplementary material). Preliminary analyses were done to determine the order for the Legendre polynomials (Supplemental Table S1; https:// doi.org/10.3168/jds.2016-11894). For the time $t$ (within episode) and DIM, third- and second-order polynomials, respectively, were found to fit best to our data (Supplemental Table S2; https://doi.org/10.3168/ jds.2016-11894). The lactation curve was also modeled with second-order polynomials. Cow permanent environmental effect (PE) was added to the model to account for the repetitive nature of transition records from a cow. Further phenotypic analyses were performed to test the interaction of regressions with parity (Supplemental Table S3; https://doi.org/10.3168/jds.201611894). The final model, chosen for the analysis of the data, therefore, included parity (1-3) and herd (1-7) as fixed effects, and sire or animal genetic, cow permanent environmental, herd-test-week, and cow-parity interaction as random effects. Therefore, traits were analyzed with the following threshold sire models:

Mastitis susceptibility (HD) was modeled as

$$
\begin{aligned}
\operatorname{Pr}\left(y_{i j k l m n}^{H D}=1\right)= & \operatorname{Pr}\left(\lambda_{i j k l m n}^{H D}<0\right) \text { and } \lambda_{i j k l m n}^{H D}=p_{i}^{H D}+h_{j}^{H D} \\
& +h t w_{k}^{H D}+c p_{l}^{H D}+\sum_{x=1}^{q} \beta_{1 i x} \phi_{1 x}(t)^{H D} \\
& +\sum_{x=1}^{q} \beta_{2 i x} \phi_{2 x}(D I M)^{H D}+p e_{m}^{H D}+s_{n}^{H D} \\
& +e_{i j k l m n}^{H D} ;
\end{aligned}
$$

and recovery ability (DH) was modeled as

$$
\begin{aligned}
\operatorname{Pr}\left(y_{i j k l m n}^{D H}=1\right)= & \operatorname{Pr}\left(\lambda_{i j k l m n}^{D H}<0\right) \text { and } \lambda_{i j k l m n}^{D H}=p_{i}^{D H}+h_{j}^{D H} \\
& +h t w_{k}^{D H}+c p_{l}^{D H}+\sum_{x=1}^{q} \beta_{1 i x} \phi_{1 x}(t)^{D H} \\
& +\sum_{x=1}^{q} \beta_{2 i x} \phi_{2 x}(D I M)^{D H}+p e_{m}^{D H}+s_{n}^{D H} \\
& +e_{i j k l m n}^{D H},
\end{aligned}
$$

where $y_{i j k l m n}^{H D}$ was a time $t$ dependent transition score (1 if a transition from $\mathrm{H}$ to $\mathrm{D}$ occurred, otherwise 0 ) for cow $m$, daughter of sire $n$, for parity $i$, herd $j$, herd-testweek $k ; y_{i j k l m n}^{D H}$ was a time $t$ dependent transition score $(1$ if a transition from $\mathrm{D}$ to $\mathrm{H}$ occurred, otherwise 0 ) for cow $m$, daughter of sire $n$, for parity $i$, herd $j$, herd-testweek $k ; \lambda_{i j k l m n}^{H D}$ and $\lambda_{i j k l m n}^{D H}$ were time-dependent HD and $\mathrm{DH}$, respectively, at time $t$, for cow $m$, daughter of sire $n$, for parity $i$, herd $j$, herd-test-week $k ; p_{i}^{H D}$ and $p_{i}^{D H}$ were fixed effects of parity $i$ for $\mathrm{HD}$ and $\mathrm{DH}$, respectively; $h_{j}^{H D}$ and $h_{j}^{D H}$ were fixed effects of herd $j$ for HD and $\mathrm{DH}$, respectively; $h t w_{k}^{H D}$ and $h t w_{k}^{D H}$ were random effects of herd-test-week $k$ for $\mathrm{HD}$ and $\mathrm{DH}$, respectively; $c p_{l}^{H D}$ and $c p_{l}^{D H}$ were random effects of cow-parity interaction $l$ for $\mathrm{HD}$ and $\mathrm{DH}$, respectively, $q=$ number of covariates describing the shape of the lactation curve ( $q$ $=1,2,3) ; \phi_{1 x}(t)^{H D}$ and $\phi_{1 x}(t)^{D H}=\left[\begin{array}{llll}c 0 & c 1 & c & c\end{array}\right]$, representing third-order Legendre polynomials on time $t$ for $\mathrm{HD}$ and $\mathrm{DH}$, respectively; $\beta_{1 i x}=$ corresponding regression coefficients nested within the $i$ th parity $(i=1,2$, $3 ; \phi_{2 x}(D I M)^{H D}$ and $\phi_{2 x}(D I M)^{D H}$ were $[\mathrm{c} 0 \mathrm{c} 1 \mathrm{c} 2 \exp (-0.05$ $\times$ DIM)], where $\mathrm{c} 0, \mathrm{c} 1$, and $\mathrm{c} 2$ represent second-order 
Legendre polynomials on DIM and $\exp (-0.05 \times$ DIM $)$ represents the Wilmink term (Wilmink, 1987) for HD and $\mathrm{DH}$, respectively; $\beta_{2 i x}=$ corresponding regression coefficients nested within the $i$ th parity $(i=1,2,3)$; $p e_{m}^{H D}$ and $p e_{m}^{D H}$ were random permanent effects of cow $m$ for HD and DH, respectively; $s_{n}^{H D}$ and $s_{n}^{D H}$ were random genetic effects of sire $n$ for $\mathrm{HD}$ and $\mathrm{DH}$, respectively; and $e_{i j k l m n}^{H D}$ and $e_{i j k l m n}^{D H}$ were random residual effects associated with $\lambda_{i j k l m n}^{H D}$ and $\lambda_{i j k l m n}^{D H}$, respectively.

The transitions were also analyzed with threshold animal models. The animal model components were the same as in equation [2] and [3] for the $\mathrm{HD}$ and $\mathrm{DH}$ traits, respectively, except that sire genetic effects $\left(s_{n}^{H D}, s_{n}^{D H}\right)$ were replaced with the animal genetic effects $\left(a_{m}^{H D}, a_{m}^{D H}\right)$.

Herd and parity were fitted as fixed effects, and the regression coefficients of the Legendre polynomials were fitted as covariates. See Appendix for model assumptions and pedigree information.

Analyses were performed using the statistical software package RJMC in DMU (Madsen and Jensen, 2013), which implements Bayesian procedures and Gibbs sampling to estimate (co)variance components. For both the fixed (herd and parity) and co-variable (regression coefficients of the Legendre polynomials) effects and the variance components for random effects, flat priors were used. Estimation of fixed effects, breeding values, and (co)variance components were based on 5,000 samples from a single chain of 250,000 iterations with a burn-in of 50,000 and samples stored at every 50th round. Sample size and length of burn-in were decided after check of convergence of posterior parameters (on visual inspections of trace plots) using the Bayesian Output Analysis (BOA) software package (Smith, 2007) in R (R Core Team, 2016).

Within-herd heritabilities were calculated from each saved Markov chain Monte Carlo (MCMC) sample as follows:

$$
\begin{aligned}
& h_{i}^{2}=\frac{4 \sigma_{s(i)}^{2}}{\sigma_{s(i)}^{2}+\sigma_{c p(i)}^{2}+\sigma_{p e(i)}^{2}+1}, \\
& h_{i}^{2}=\frac{\sigma_{a(i)}^{2}}{\sigma_{a(i)}^{2}+\sigma_{c p(i)}^{2}+\sigma_{p e(i)}^{2}+1},
\end{aligned}
$$

for the sire and animal models, respectively, where $\sigma_{s(i)}^{2}$ $=$ posterior sire variance at MCMC iteration $i$ for $i=$ $1,2,3, \ldots, 5,000 ; \sigma_{a(i)}^{2}=$ posterior additive genetic variance at MCMC iteration $i$ for $i=1,2,3, \ldots, 5,000$; $\sigma_{c p(i)}^{2}=$ posterior cow-parity interaction variance at MCMC iteration $i$ for $i=1,2,3, \ldots, 5,000 ; \sigma_{p e(i)}^{2}=$ posterior cow permanent environmental variance at MCMC iteration $i$ for $i=1,2,3, \ldots, 5,000$.

Heritabilities calculated from each MCMC sample were used to calculate the posterior mean of heritabilities for $\mathrm{HD}\left(h_{H D}^{2}\right)$ and $\mathrm{DH}\left(h_{D H}^{2}\right)$. Posterior mean of standard deviations (PSD) were also calculated from each posterior MCMC sample.

Similarly, posterior mean of repeatabilities for HD and $\mathrm{DH}$ were calculated from the posterior variance components as follows:

$$
\text { Repeatability }=\frac{\left[\sigma_{a(i)}^{2} \text { or } \sigma_{s(i)}^{2}\right]+\sigma_{p e(i)}^{2}}{\left[\sigma_{a(i)}^{2} \text { or } \sigma_{s(i)}^{2}\right]+\sigma_{c p(i)}^{2}+\sigma_{p e(i)}^{2}+1},
$$

where all terms were as defined in equation [4].

Genetic correlations between HD and DH for the sire and animal models, respectively, were calculated as

$$
\begin{gathered}
r_{s}=\frac{\sigma_{s_{H D, D H}}}{\sqrt{\sigma_{s_{H D}}^{2} \times \sigma_{s_{D H}}^{2}}}, \\
r_{g}=\frac{\sigma_{a_{H D, D H}}}{\sqrt{\sigma_{a_{H D}}^{2} \times \sigma_{a_{D H}}^{2}}} .
\end{gathered}
$$

Permanent environmental effect correlation $\left(r_{p e}\right)$ between HD and DH for a cow was calculated as

$$
r_{p e}=\frac{\sigma_{p e_{H D, D H}}}{\sqrt{\sigma_{p e_{H D}}^{2} \times \sigma_{p e_{D H}}^{2}}} .
$$

Cow-parity interaction effect correlation $\left(r_{c p}\right)$ between $\mathrm{HD}$ and $\mathrm{DH}$ was calculated as

$$
r_{c p}=\frac{\sigma_{c p_{H D, D H}}}{\sqrt{\sigma_{c p_{H D}}^{2} \times \sigma_{c p_{D H}}^{2}}} .
$$

Herd-test-week effect correlation $\left(r_{h t w}\right)$ between HD and DH was calculated as

$$
r_{h t w}=\frac{\sigma_{h t w_{H D, D H}}}{\sqrt{\sigma_{h t w_{H D}}^{2} \times \sigma_{h t w_{D H}}^{2}}} .
$$


Table 2. Mastitis incidence and recovery rate by lactation defined by the number of transition records for susceptibility (healthy to diseased, $\mathrm{HD}$ ) to and recovery (diseased to healthy, DH) from mastitis

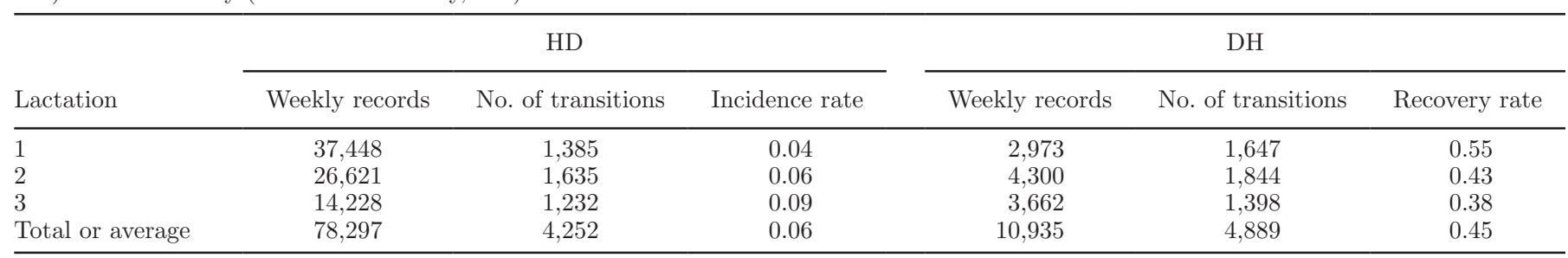

Odds ratios $(\mathbf{O R})$ were calculated to demonstrate the influence of fixed effects on the 2 traits. We calculated OR for parity and herd relative to parity 1 and herd 1 considered as reference classes for parity and herd, respectively. The OR from logistic regressions were obtained by taking the exponential function of estimates. However, as our estimates were from a probit model, we multiplied the estimates by 1.81 (approximation of $\pi / \sqrt{ } 3$; Powers and Xie, 2000). An OR $>1$ indicates that the specified factor has an increased risk over the reference value (Green et al., 2007; Pantoja et al., 2009).

\section{RESULTS}

\section{Descriptive Statistics}

On average, over 3 lactation periods, mastitis incidence (defined by transitions from healthy to diseased status) was $6 \%$ per lactation. As expected, risk of becoming diseased was lowest in lactation 1 and highest in lactation 3 (Table 2 ). The average recovery rate (defined by transitions from diseased to healthy status) over 3 lactations was $45 \%$ (Table 2).

The summary of the phenotypic data showed an elevated risk of becoming diseased in early lactation, but the risk remained stable during the remainder of the lactation (Figure 2). The proportion of cows infected was highest in later lactations (Figure 2) and during the first week of an episode. The susceptibility to mastitis decreased with time (within episode): it decreased quite quickly during the first weeks of an episode and remained stable afterward (Figure 3). The proportion of cows recovered was shown to decline in later lactations (Figure 4). Recovery was highest in early lactation, lowest in mid lactation, and increased again toward the end of lactation. Recovery rate was highest in the first weeks (within lactation) after mastitis was observed (Figure 5).

\section{Model Effects and Genetic Parameters}

Our initial phenotypic analyses showed that all random effects were significant for both traits suscep- tibility to (HD) and recovery from (DH) mastitis, as determined by deviance information criteria values.

We detected considerable variation among cows for both traits. The variation among cows was higher for $\mathrm{HD} \quad\left(\sigma_{a}^{2}=0.09, \mathrm{PSD}=0.02\right) \quad$ than for $\mathrm{DH}$ $\left(\sigma_{a}^{2}=0.07, \mathrm{PSD}=0.02\right)$ in the animal model (Table 3 ). In general, the posterior means of the variances for $\mathrm{HD}$ were higher than those for DH except for the herd-testweek variance in both the sire and animal models (Table $3)$. The posterior mean of heritabilities for HD $\left(h_{H D}^{2}=0.07, \mathrm{PSD}=0.03\right.$ and $\left.\mathrm{PSD}=0.02\right) \quad(\mathrm{PSD}$ from the sire and animal models, respectively), and the posterior mean of heritabilities for $\mathrm{DH}$ $\left(h_{D H}^{2}=0.08, \mathrm{PSD}=0.03 ; h_{D H}^{2}=0.06, \mathrm{PSD}=0.02\right)($ from the sire and animal models, respectively) were of similar size (Table 3). Posterior mean of repeatabilities for HD from the sire and animal models were essentially the same (repeatability $=0.11$, PSD $=0.01$ ). The posterior mean of repeatabilities for $\mathrm{HD}$ and $\mathrm{DH}$ were of similar size in both models (Table 3 ).

The posterior mean of genetic correlations between the traits were negative for all animal-related random effects (Table 4). This indicates that cows that easily contract mastitis will not recover easily. The correlation between HD and DH for the herd-test-week effect included zero in the $95 \%$ credibility intervals in both the sire and animal models (Table 4). Whereas high susceptibility was associated with slow recovery at animal level, a close-to-zero correlation for the herdtest-week effect $\left(r_{h t w}=0.05, \mathrm{PSD}=0.16\right)$ suggested that this was different at the herd (management) level: recovery could be fast even though susceptibility was high at herd level.

Estimates of the effect of co-variables and fixed effects from the animal model were similar in trends to the estimates from the sire model. Below we present parity as risk factor only from the sire model. Compared with the reference class $(\mathrm{OR}=1$, parity 1$)$, later parities had a higher risk of mastitis $(\mathrm{OR}=2.87$ for parity 3 and $\mathrm{OR}=1.75$ for parity 2 ; Figure 6 ). Later parities $(\mathrm{OR}=0.40$ for parity 3 and $\mathrm{OR}=0.59$ for 


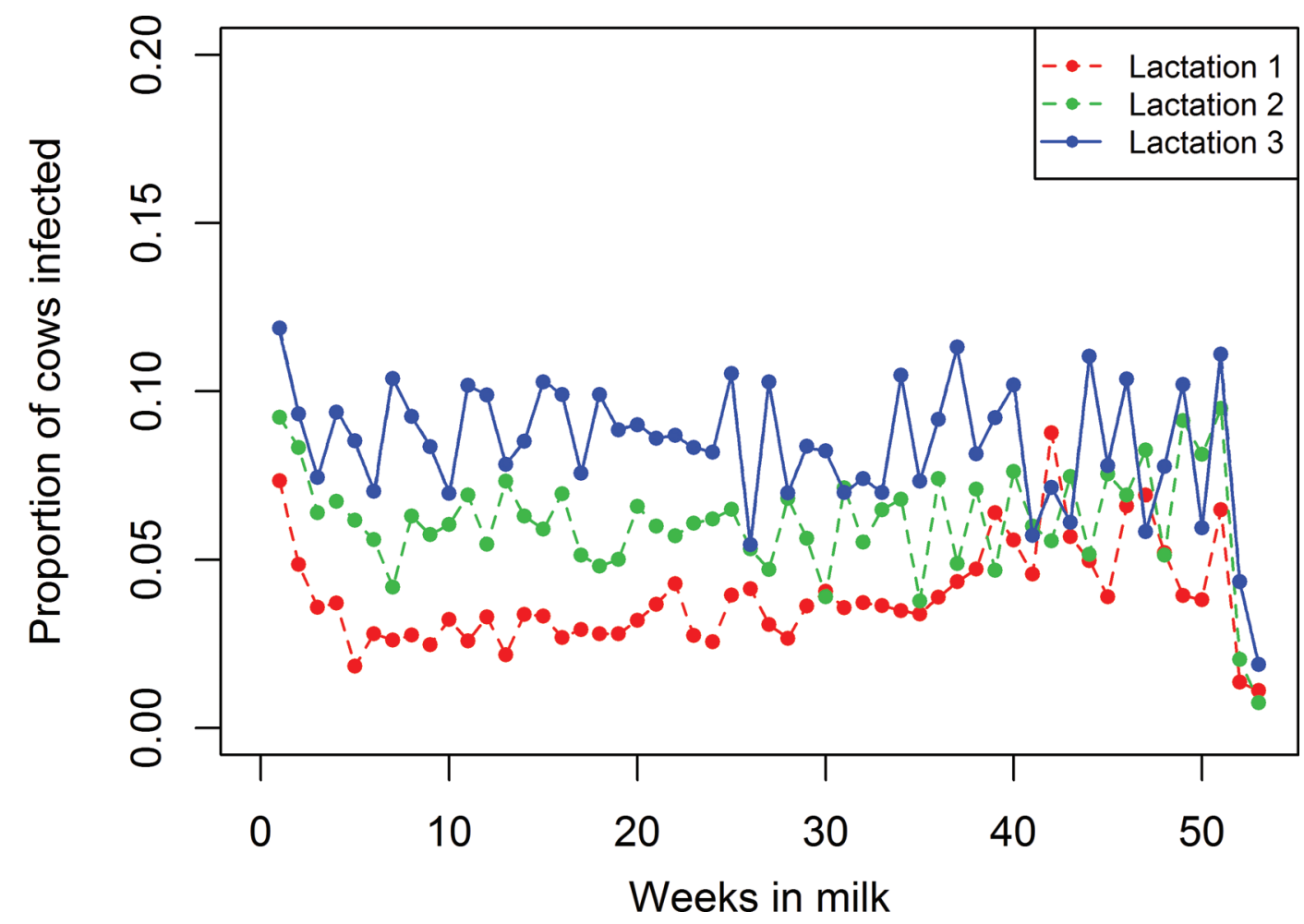

Figure 2. Lactation effect on mastitis susceptibility. Proportion of cows becoming infected was highest in later lactations (lactation 3, blue line) and lowest in first lactation (lactation 1, red line). Color version available online.

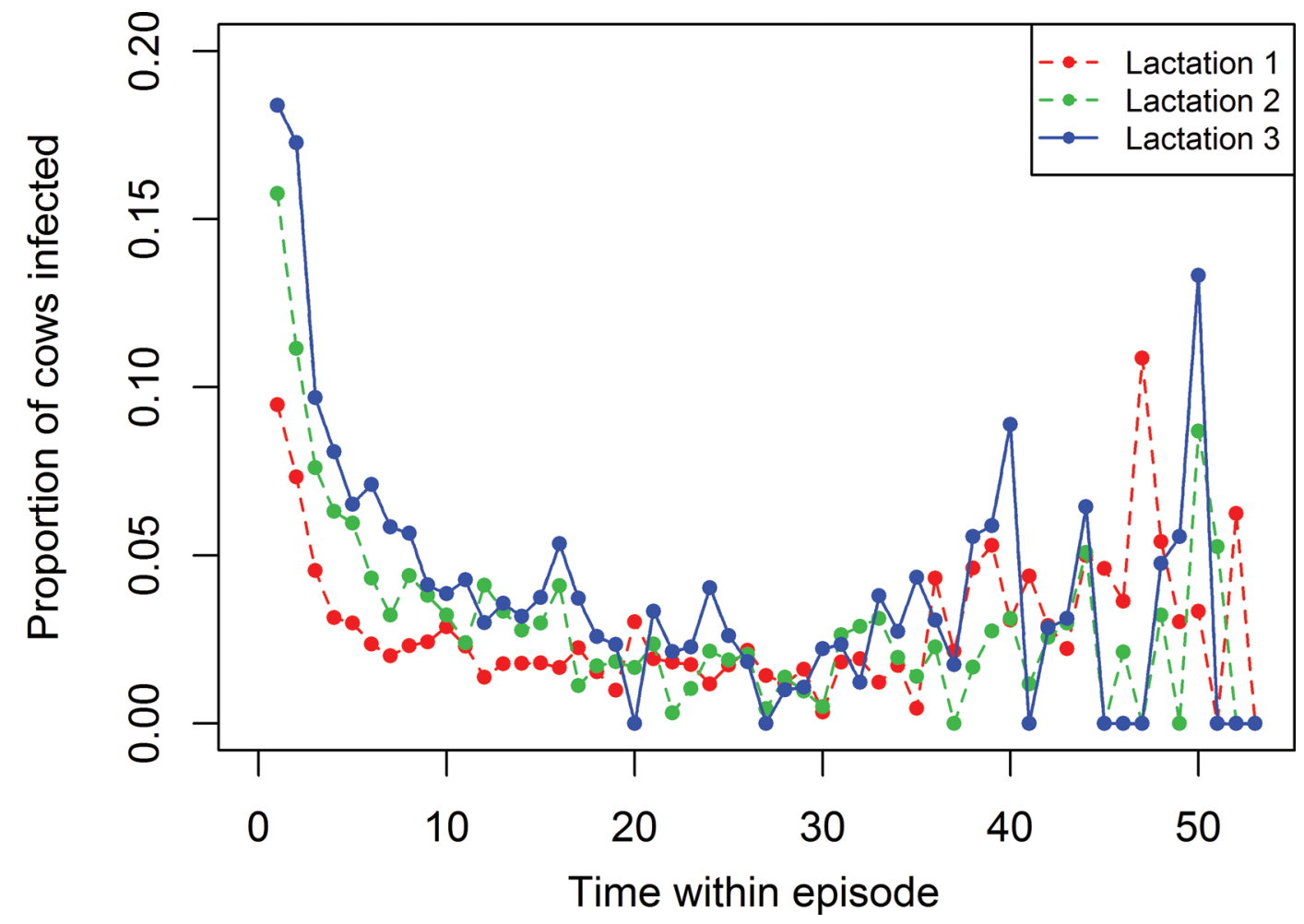

Figure 3. Mastitis susceptibility as a function of time (in weeks) within episode. Proportion of cows becoming infected was highest during the first week of an episode. Color version available online. 


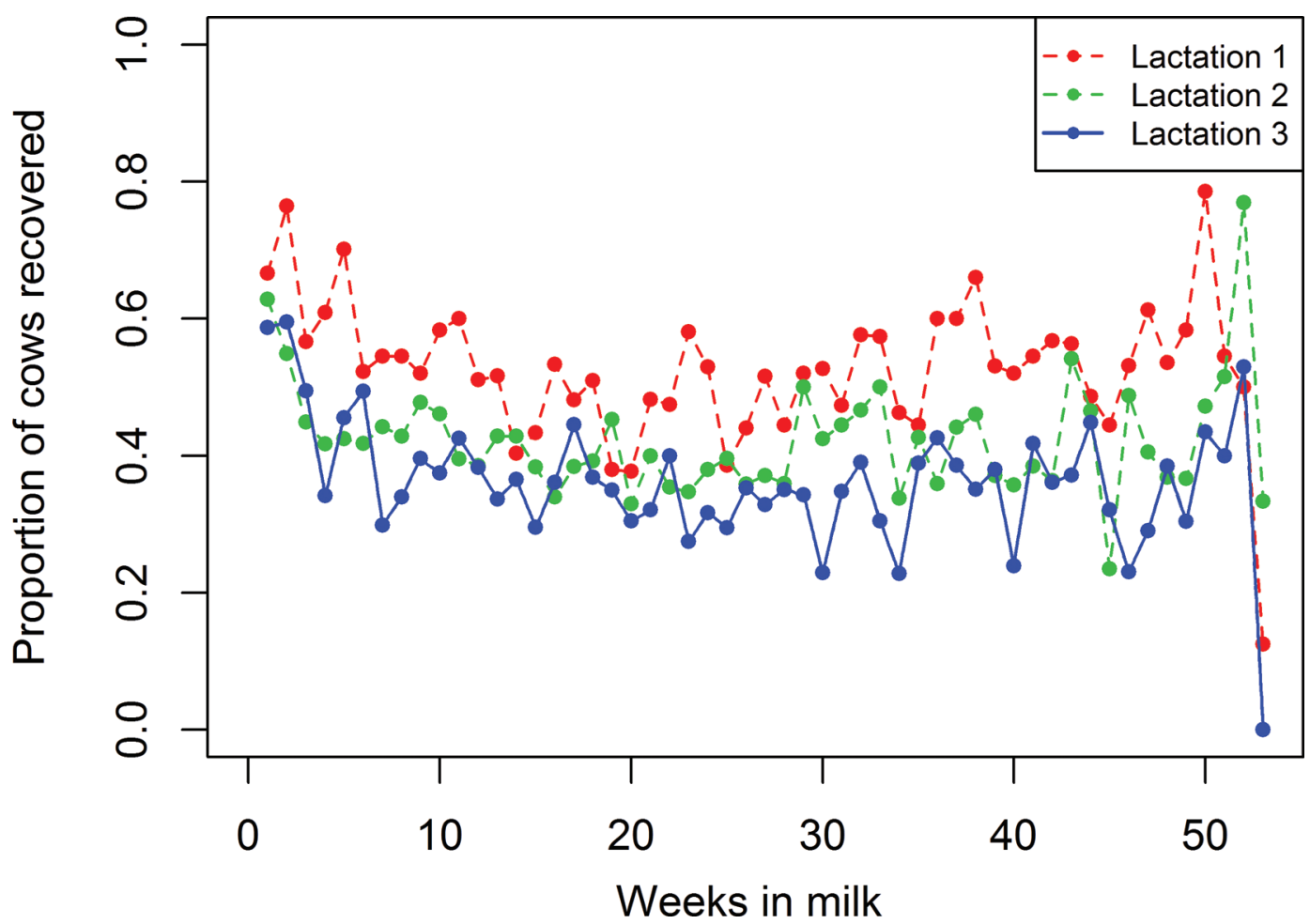

Figure 4. Lactation effect on ability to recover from mastitis. Proportion of cows recovered was lowest in later lactations (lactation 3, blue line) and highest in first lactation (lactation 1, red line). Color version available online.

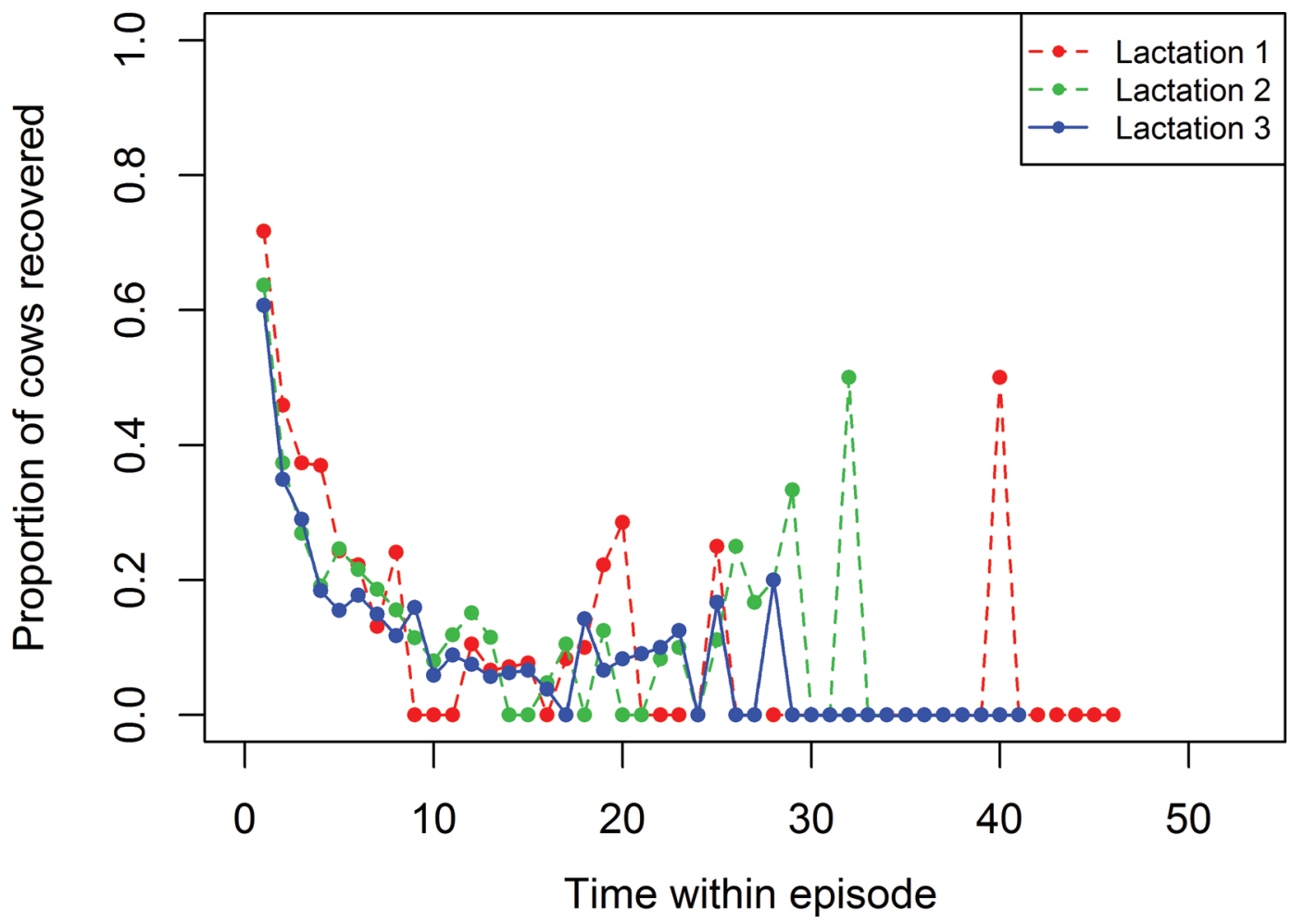

Figure 5. Recovery ability as function of time (in weeks) within episode. There was high recovery rate (up to 70\%) during the first weeks of an episode. Color version available online. 
Table 3. Posterior mean (SD) of variance components for the random effects, heritability, and repeatability from the sire and animal models for susceptibility (healthy to diseased, HD) to and recovery (diseased to healthy, DH) from mastitis

\begin{tabular}{lccccc}
\hline \multirow{2}{*}{$\begin{array}{l}\text { Variance } \\
\text { components }\end{array}$} & \multicolumn{2}{c}{ Sire model } & & \multicolumn{2}{c}{ Animal model } \\
\cline { 2 - 3 } \cline { 5 - 6 } & $\mathrm{HD}$ & $\mathrm{DH}$ & & $\mathrm{HD}$ & $\mathrm{DH}$ \\
\hline$\sigma_{s}^{2}$ or $\sigma_{a}^{2}$ & $0.02(0.01)$ & $0.03(0.01)$ & & $0.09(0.02)$ & $0.07(0.02)$ \\
$\sigma_{p e}^{2}$ & $0.12(0.02)$ & $0.09(0.02)$ & & $0.05(0.02)$ & $0.05(0.02)$ \\
$\sigma_{c p}^{2}$ & $0.18(0.02)$ & $0.13(0.03)$ & & $0.18(0.02)$ & $0.12(0.03)$ \\
$\sigma_{h t w}^{2}$ & $0.02(0.00)$ & $0.06(0.01)$ & & $0.02(0.00)$ & $0.06(0.01)$ \\
Heritability & $0.07(0.03)$ & $0.08(0.03)$ & & $0.07(0.02)$ & $0.06(0.02)$ \\
Repeatability & $0.11(0.01)$ & $0.09(0.02)$ & & $0.11(0.01)$ & $0.10(0.02)$ \\
\hline
\end{tabular}

${ }^{1}$ Variance components: $\sigma_{s}^{2}$ or $\sigma_{a}^{2}=$ sire or animal additive genetic variance, $\sigma_{p e}^{2}=$ cow permanent environmental variance, $\sigma_{c p}^{2}=$ cow-parity interaction variance, and $\sigma_{h t w}^{2}=$ herd-test-week variance.

parity 2) were also associated with lower recovery rates (Figure 6).

\section{DISCUSSION}

In the genetic evaluation of udder health, susceptibility to mastitis has been the focus of many dairy cattle research projects, disregarding the other aspect of the disease - the ability to recover. Fast recovery may promote cows to return quickly to normal levels of production, feed intake, and behavior, as these are traits reported to be affected in mastitic cows (Fogsgaard et al., 2015a). Because mastitis is a relatively frequent and unavoidable problem, evaluation of an animal's ability to recover should, therefore, be of interest. Recent studies (Franzén et al., 2012; Fogsgaard et al., 2015b; Welderufael et al., 2017) have proposed the introduction of the recovery aspect as a new trait in analyses to enhance the genetic evaluation of udder health by captur-

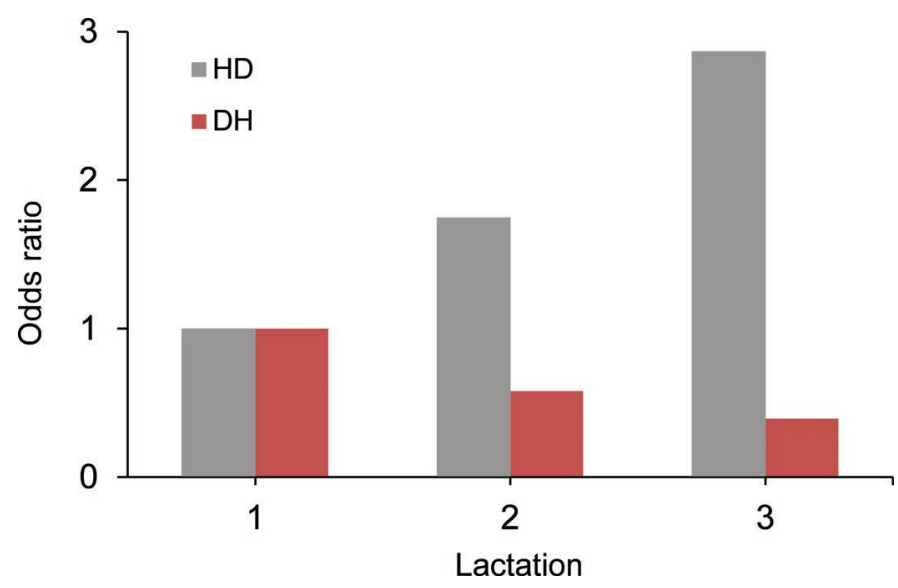

Figure 6. Odds ratio of parity effect (parity 1 as reference) for susceptibility (healthy to diseased, HD) to and recovery ability (diseased to healthy, DH) from mastitis. Color version available online. ing as much genetic information as possible from the entire disease course. The current study incorporated those ideas by analyzing the changes in SCC that each cow exhibits during lactation in a simultaneous evaluation of the genetic potential of both $\mathrm{HD}$ and $\mathrm{DH}$. In situations with high mastitis prevalence, evaluating the capacity of cows for recovery could be of specific benefit to the dairy industry. Urioste et al. (2012) analyzed average days diseased (per lactation) in Swedish Holstein cows as a trait: the length of a disease episode was determined as the number of days between the start and the end of an infection peak (test-day with SCC $<150,000$ cells $/ \mathrm{mL}$ and having at least one test-day with $>150,000$ cells $/ \mathrm{mL}$ in between, with weekly observations of SCC), and the average (per lactation) was determined as the total number of days diseased divided by the total number of peaks divided by the number of peaks. On average, cows remained diseased for $56.9,82.9$, and $99.8 \mathrm{~d}$ in parities 1,2 , and 3 , respectively. The increase in days diseased for later parities is comparable with the trend for DH trait observed in the current study, where recovery rate was highest in parity 1 (fewer days diseased) and lowest in parity 3 (more days diseased). Urioste et al. (2012) analyzed the days diseased (log-transformed) with a linear animal model and reported parity-specific heritabilities for average days diseased that ranged from 0.06 to 0.17 , with lower heritability for late parity and higher heritability for earlier parity. Both the results by Urioste et al. (2012) and our heritability estimates from the $\operatorname{sire}\left(h_{D H}^{2}=0.08\right)$ and animal $\left(h_{D H}^{2}=0.06\right)$ models support the presence of heritable variation in recovery ability from mastitis.

A review by Heringstad et al. (2000) indicated that estimates of heritability for susceptibility to CM from threshold models ranged from 0.06 to 0.12 . Other studies (de Haas et al., 2008; Koeck et al., 2010) showed that heritability of SCC-based traits ranged from 0.09 
Table 4. Posterior mean (SD) and 95\% highest posterior densities (HPD) of correlations between mastitis susceptibility and recovery ability for the random effects from sire and animal models

\begin{tabular}{|c|c|c|c|c|c|c|}
\hline \multirow[b]{3}{*}{ Correlation $^{1}$} & \multicolumn{3}{|c|}{ Sire model } & \multicolumn{3}{|c|}{ Animal model } \\
\hline & \multirow[b]{2}{*}{ Mean } & \multicolumn{2}{|c|}{ HPD } & \multirow[b]{2}{*}{ Mean } & \multicolumn{2}{|c|}{ HPD } \\
\hline & & Lower & Upper & & Lower & Upper \\
\hline$r_{s}$ or $r_{g}$ & $-0.83(0.13)$ & -0.99 & -0.54 & $-0.90(0.08)$ & -1.00 & -0.75 \\
\hline$r_{p e}$ & $-0.90(0.07)$ & -1.00 & -0.76 & $-0.80(0.21)$ & -1.00 & -0.41 \\
\hline$r_{c p}$ & $-0.30(0.10)$ & -0.50 & -0.10 & $-0.31(0.11)$ & -0.51 & -0.10 \\
\hline$r_{h t w}$ & $0.05(0.16)$ & -0.26 & 0.38 & $0.05(0.16)$ & -0.26 & 0.38 \\
\hline
\end{tabular}

to 0.13 , which is consistent with the heritability estimate $\left(h_{H D}^{2}=0.07\right)$ from the sire and animal models in the present study. Our heritability estimates for HD also agree with earlier reports of heritability for susceptibility to CM (0.08 to 0.15 from threshold models; Hinrichs et al., 2011) for Holstein cows. Despite differences in analyses and definitions of SCC-related traits, results from several previous reports (Lassen et al., 2003; de Haas et al., 2008; Koeck et al., 2010) and our estimates fell within the range of estimates presented by Heringstad et al. (2000).

Survival models have been used as an alternative model for genetic evaluation of mastitis (Carlén et al., 2005; Schukken et al., 2010; van den Borne et al., 2011). Occurrence and timing of specific events (e.g., time to mastitis) can be fitted easily in survival models. Carlén et al. (2005) compared linear models and survival analysis using data from first 3 lactations of Swedish Holstein cows. For the survival analyses, they reported heritability estimates of 0.03 to 0.04 , which is much lower than our corresponding estimate $\left(h_{H D}^{2}=0.07\right)$. It is important to note that heritabilities of different models are only comparable if expressed on the same scale. Carlén et al. (2005) reported "equivalent" heritability as defined by Yazdi et al. (2002) for Weibull survival models. Our model is conceptually equivalent to a survival analysis, and would assume a Weibull distribution if only a linear regression on $\log (t)$ had been included (Allison, 1982). Because we used higher-order polynomials for $t$, the approximations developed by Yazdi et al. (2002) to express heritability such that they do not depend on the parameters of the model may not be applicable for our case. In "ideal" scenarios, analyzing simulated data, the Weibull survival model and our approach yielded similar heritabilities (c.f. Carlén et al., 2005 and Welderufael et al., 2017).

In the sire model, the permanent environmental variance $\left(\sigma_{p e_{H D}}^{2}=0.12\right)$ includes three-fourths of the genetic variance. Therefore, the comparable $\sigma_{p e_{H D}}^{2}(0.12-3 \times$ $0.02=0.06)$ from the sire model is not much different from the estimate of the animal model $\left(\sigma_{p e}^{2}=0.05\right)$. If the repeatability is much larger than the heritability, this would indicate that nongenetic factors influence repeated occurrence of either susceptibility or recovery during lactations (Gernand et al., 2012). With the repeatability being less than twice the heritability, we can assert that genetics is the predominant factor among the "cow" effects. The higher herd-test-week variance for $\mathrm{DH}\left(\sigma_{h t w_{D H}}^{2}=0.06\right)$ than for $\mathrm{HD}\left(\sigma_{h t w_{H D}}^{2}=0.02\right)$ in both models indicates that treatment methods and herd management effects would make a greater difference for recovery than for susceptibility to mastitis. In other words, management to prevent mastitis (influencing susceptibility) is stable across time, whereas management related to recovery appears more variable. Therefore, results suggest that it may be possible to improve recovery rates through improvements of herd management (e.g., improvements in veterinary treatments).

The genetic correlation between $\mathrm{HD}$ and $\mathrm{DH}$ from the sire $\left(r_{s}=-0.83\right)$ and animal $\left(r_{g}=-0.90\right)$ models were strongly negative. Urioste et al. (2012) reported strong positive genetic correlations (0.97) between average days diseased and average SCC in early lactation (5-150 d), implying that in genetic terms either of the traits could be explained by the other one. The strong negative genetic correlations observed in this study could point to a single underlying genetic mechanism affecting both HD and DH. However, the observed genetic correlation between $\mathrm{HD}$ and $\mathrm{DH}$ is not complete (i.e., 1), meaning there may be some merit in also selecting for recovery. The strong negative PE correlations, $r_{p e}=-0.90$ (sire model) and -0.80 (animal model), suggest that the recovery process will not be easy for a cow that gets mastitis easily. With such unfavorable correlations, a highly susceptible cow 
takes longer and may require veterinary treatment to recover. When a treatment (antibiotic) is given, it may boost the ability to recover, and thereby combat the infection. In our studies, we did not consider treatment, but we observed good correlation between recovery and contraction. By ignoring treatment, we assume that all treatment effects were equal for every animal. It is hard to understand the strong genetic and environmental correlations from a biological angle. The susceptibility to mastitis depends largely on the innate immune system, which is the first line of defense. A major part of the innate immune system is the white blood cell population (leukocytes), made up of immune cells such as neutrophils, macrophages, and natural killer cells (Sordillo and Streicher, 2002; Oviedo-Boyso et al., 2007). It is these leukocytes, in fact, that make up the SCC used to monitor mastitis infections. In the recovery process, we expect a contribution from the adaptive immune system, where specific antibodies are targeting the pathogen (Sordillo and Streicher, 2002; Oviedo-Boyso et al., 2007). If there is indeed a common biological process behind the high correlations, there could be a role for the macrophages that are part of the innate immune system but also play a key role in priming the adaptive immune response (Sordillo and Streicher, 2002; Oviedo-Boyso et al., 2007). Because different pathogens invoke a different immune response (Oviedo-Boyso et al., 2007), it would be interesting to study susceptibility and recovery for specific pathogens instead on the basis of SCC. However, it may be some time before we get pathogen-specific measures in sufficient quantities to facilitate genetic analyses.

Although there are concerns about the robustness of the animal model when used in combination with a threshold model (e.g., Wang, 1998; Luo et al., 2001), the comparison with results from a sire model showed similar results. Using the current data, estimated variance components from the sire and animal models with Gibbs sampling were of similar size. However, Sun et al. (2009) indicated that an animal model could yield increased stability and accuracy of sire genetic evaluation of fertility traits in dairy cattle compared with the sire model. This is because the animal model allows all relatives (including the cow's own record) to contribute information to the evaluation, whereas the sire model uses less information on relatives. It is generally preferred to use an animal model for genetic evaluation, and in the case of mastitis susceptibility and recovery, because it better adjusts for selection and nonrandom mating and provides breeding values for females.

In the Nordic countries, mastitis incidence rates per lactation vary between 0.2 and 0.4 (Heringstad et al., 2000). Sato et al. (2008) reported a mean rate of 44.7 cases per 100 cow-years for CM in Danish dairy herds.
The mean incidence rate of $6 \%$ per lactation observed in present study is much lower than the values in those reports. From data sets of 300 d of lactation analyzed with a multiple threshold lactation model, Hinrichs et al. (2011) reported a mastitis incidence of $39.2 \%$ for 3 commercial milk farms with an average herd size of 3,200 German Holstein cows. On the other hand, Yin et al. (2014) reported a low mastitis incidence of $5.8 \%$ for a time span of $120 \mathrm{~d}$ for primiparous Brown Swiss cows kept in 53 organic and low-input farms in Switzerland. Differences in trait definition, parity, stage of lactation, herd, and season are among other possible factors for variation in incidences of mastitis reported (Hinrichs et al., 2011; Gernand et al., 2012; Yin et al., 2014).

The current result shows that incidence of mastitis increases across lactations and is most frequent in the first weeks of lactations. Similar patterns across and within lactations were reported by Gernand et al. (2012) for different dairy cow disease traits, including mastitis. Our results confirm that mastitis incidence is most frequent in the first weeks of lactation (de Haas et al., 2002; Nyman et al., 2007) and different between lactations (Sargeant et al., 1998). The patterns of mastitis incidence across and within lactations were comparable to those of previous studies (Emanuelson et al., 1993; Sargeant et al., 1998). The sharp decline in mastitis incidence after the first few weeks in lactation is an indication that for a cow that has been healthy for several weeks, the risk of getting mastitis is low. The risk of becoming diseased is highest at the start of a healthy period (at the beginning of lactation, or just after recovery). After parturition, the neutrophil cell population is imbalanced, resulting in increased susceptibility to mastitis (reviewed by Sordillo and Streicher, 2002). Reinfection shortly after initial recovery may indicate incomplete clearance of the pathogen or re-infection because of a compromised immune system.

In several studies (Carlén et al., 2004; Steeneveld et al., 2008; Wolf et al., 2010), SCC-based traits were defined from lactation mean SCC or lactation mean SCS. However, results from other studies (Negussie et al., 2008; Koeck et al., 2010) suggest that CM and SCS in an interval may have a more similar genetic basis than CM and SCS in a different interval; therefore, the application of test-day (longitudinal) models for SCS would be more appropriate. A longitudinal model can give a dynamic description of the genetic relationship between SCS and CM in the course of lactation (Koeck et al., 2010; Franzén et al., 2012). Our approach adopted these models, considering time-dependent variables and lactation effect to model time-dependent transitions. It matters, for example, whether a mastitis case occurs early or late in lactation, something that our approach accounts for. In addition, the longitudinal approach 
enables the use of herd-test-week as a contemporary group, implying that only observations that were subject to the same (herd) environment are compared, in contrast to cross-sectional models, where contemporary groups often are defined based on season of calving.

Misclassifications are unavoidable when SCC is used as an indicator for mastitis. If the boundary between healthy and diseased is too low, high random fluctuations around "normal" SCC levels will lead to falsely classified cases of mastitis (Franzén et al., 2012). Bishop and Woolliams (2010) demonstrated that nongenetic factors such as imperfect sensitivity and specificity of diagnosis are likely to affect genetic parameters for disease traits. The choice of EMR threshold can affect the model's sensitivity and specificity to detect mastitis cases. Sørensen et al. (2016) evaluated 5 threshold values $(\mathrm{EMR}=0.5,0.6,0.7,0.8$, and 0.9$)$ by comparing with confirmed (veterinary-treated) cases and found, for most validation parameters, an EMR threshold value of 0.6 to be the optimal choice for sensitivity and specificity. We repeated our analysis with a higher EMR threshold $($ EMR $=0.8)$ and observed negligible effect on the genetic parameters. For example, posterior means of heritability for HD from the sire and animal models (unreported results) were approximately equivalent to the heritability estimate from the lower threshold value $(\mathrm{EMR}=0.6)$ presented in Table 3. Differences in genetic correlation between HD and DH from the estimates using the lower threshold were also marginal (unreported results). In addition to studying the sensitivity of the model for the choice of threshold, one aspect for using different thresholds is that EMR = 0.8 probably only captures $\mathrm{CM}$, and $\mathrm{EMR}=0.6$ may capture some subclinical mastitis cases as well. Instead of imposing a fixed threshold to define health states, Detilleux (2011) applied a simple hidden Markov model on SCS from cows with or without CM to evaluate its accuracy in estimating parameters under healthy or diseased states. She compared 3 different health-related states: CM, subclinical mastitis (defined for SCC below or above 250,000 cells $/ \mathrm{mL}$ ), and infected stages derived from the model. The results of Detilleux (2011) showed that the model identifies infected cows before the appearance of clinical and subclinical signs.

The results presented herein lead us to different avenues of investigation for potential further development of the methods. We can improve the classification of health states by adding more classes such as persistent infection or a new state representing subclinical mastitis and model transition probabilities between different possible states (e.g., healthy, subclinical mastitis, CM, and persistent infection). Such enhanced classification combined with advanced mathematical models (Detilleux, 2011) and action that depends on new continuous mutually exclusive udder health classes defined according to assumed disease severity, as recommended by Løvendahl and Sørensen (2016), could be considered as further potential improvements. This improves the use of information contained in SCC data by improving the accuracy of SCC measures used to identify infected cows.

\section{CONCLUSIONS}

We have developed a bivariate model for a joint estimation of genetic parameters for susceptibility to and recovery from mastitis based on OCC-based health state transition for Danish Holstein cows. Estimated heritability for susceptibility to and recovery ability from mastitis were similar, and ranged between 0.06 and 0.08. Although contraction and recovery from mastitis are strongly negatively correlated, recovery could be considered as a new trait for selection that could be of specific benefit in situations where cows contract mastitis easily. This novel modeling approach enhances the genetic evaluation of mastitis by adding recovery information to the analysis.

\section{ACKNOWLEDGMENTS}

B. G. W. benefited from a joint grant from the European Commission and Swedish University of Agricultural Sciences within the framework of the ErasmusMundus joint doctorate EGS-ABG.

\section{REFERENCES}

Allison, P. D. 1982. Discrete-time methods for the analysis of event histories. Sociol. Methodol. 13:61-98.

Bishop, S. C., and J. A. Woolliams. 2010. On the genetic interpretation of disease data. PLoS One 5:e8940. https://doi.org/10.1371/ journal.pone.0008940.

Carlén, E., U. Emanuelson, and E. Strandberg. 2006. Genetic evaluation of mastitis in dairy cattle using linear models, threshold models, and survival analysis: A simulation study. J. Dairy Sci. 89:4049-4057.

Carlén, E., M. D. Schneider, and E. Strandberg. 2005. Comparison between linear models and survival analysis for genetic evaluation of clinical mastitis in dairy cattle. J. Dairy Sci. 88:797-803.

Carlén, E., E. Strandberg, and A. Roth. 2004. Genetic parameters for clinical mastitis, somatic cell score, and production in the first three lactations of Swedish Holstein cows. J. Dairy Sci. 87:30623070 .

de Haas, Y., H. W. Barkema, and R. F. Veerkamp. 2002. The effect of pathogen-specific clinical mastitis on the lactation curve for somatic cell count. J. Dairy Sci. 85:1314-1323.

de Haas, Y., W. Ouweltjes, J. ten Napel, J. J. Windig, and G. de Jong. 2008. Alternative somatic cell count traits as mastitis indicators for genetic selection. J. Dairy Sci. 91:2501-2511.

Detilleux, J. C. 2011. A hidden Markov model to predict early mastitis from test-day somatic cell scores. Animal 5:175-181.

Emanuelson, U., B. Danell, and J. Philipsson. 1988. Genetic parameters for clinical mastitis, somatic cell counts, and milk production estimated by multiple-trait restricted maximum likelihood. J. Dairy Sci. 71:467-476.

Journal of Dairy Science Vol. 100 No. 6, 2017 
Emanuelson, U., P. A. Oltenacu, and Y. T. Grohn. 1993. Nonlinear mixed model analyses of five production disorders of dairy cattle. J. Dairy Sci. 76:2765-2772.

Fogsgaard, K. K., T. W. Bennedsgaard, and M. S. Herskin. 2015a. Behavioral changes in freestall-housed dairy cows with naturally occurring clinical mastitis. J. Dairy Sci. 98:1730-1738.

Fogsgaard, K. K., P. Løvendahl, T. W. Bennedsgaard, and S. Østergaard. 2015b. Changes in milk yield, lactate dehydrogenase, milking frequency, and interquarter yield ratio persist for up to 8 weeks after antibiotic treatment of mastitis. J. Dairy Sci. 98:7686-7698.

Franzén, J., D. Thorburn, J. I. Urioste, and E. Strandberg. 2012. Genetic evaluation of mastitis liability and recovery through longitudinal analysis of transition probabilities. Genet. Sel. Evol. 44.10. https://doi.org/10.1186/1297-9686-44-10.

Gernand, E., and S. Konig. 2014. Random regression test-day model for clinical mastitis: Genetic parameters, model comparison, and correlations with indicator traits. J. Dairy Sci. 97:3953-3963.

Gernand, E., P. Rehbein, U. U. von Borstel, and S. Konig. 2012. Incidences of and genetic parameters for mastitis, claw disorders, and common health traits recorded in dairy cattle contract herds. J. Dairy Sci. 95:2144-2156.

Gianola, D., and J. Foulley. 1983. Sire evaluation for ordered categorical data with a threshold model. Genet. Sel. Evol. 15:201-224.

Govignon-Gion, A., R. Dassonneville, G. Baloche, and V. Ducrocq. 2016. Multiple trait genetic evaluation of clinical mastitis in three dairy cattle breeds. Animal 10:558-565.

Green, M. J., A. J. Bradley, G. F. Medley, and W. J. Browne. 2007. Cow, farm, and management factors during the dry period that determine the rate of clinical mastitis after calving. J. Dairy Sci. 90:3764-3776

Halasa, T., K. Huijps, O. Osteras, and H. Hogeveen. 2007. Economic effects of bovine mastitis and mastitis management: A review. Vet. Q. 29:18-31.

Heringstad, B., G. Klemetsdal, and J. Ruane. 2000. Selection for mastitis resistance in dairy cattle: A review with focus on the situation in the Nordic countries. Livest. Prod. Sci. 64:95-106.

Hinrichs, D., J. Bennewitz, E. Stamer, W. Junge, E. Kalm, and G. Thaller. 2011. Genetic analysis of mastitis data with different models. J. Dairy Sci. 94:471-478.

Hogeveen, H., K. Huijps, and T. J. Lam. 2011. Economic aspects of mastitis: New developments. N. Z. Vet. J. 59:16-23.

Højsgaard, S., and N. C. Friggens. 2010. Quantifying degree of mastitis from common trends in a panel of indicators for mastitis in dairy cows. J. Dairy Sci. 93:582-592.

Jamrozik, J., A. Koeck, F. Miglior, G. J. Kistemaker, F. S. Schenkel, D. F. Kelton, B. J. v. Doormaal, and B. J. van Doormaal. 2013. Genetic and genomic evaluation of mastitis resistance in Canada. Interbull Bull. 47:43-51.

Koeck, A., B. Heringstad, C. Egger-Danner, C. Fuerst, P. Winter, and B. Fuerst-Waltl. 2010. Genetic analysis of clinical mastitis and somatic cell count traits in Austrian Fleckvieh cows. J. Dairy Sci. 93:5987-5995

Lassen, J., M. Hansen, M. K. Sorensen, G. P. Aamand, L. G. Christensen, and P. Madsen. 2003. Genetic relationship between body condition score, dairy character, mastitis, and diseases other than mastitis in first-parity Danish Holstein cows. J. Dairy Sci 86:3730-3735

Løvendahl, P., and L. P. Sørensen. 2016. Frequently recorded sensor data may correctly provide health status of cows if data are handled carefully and errors are filtered away. Biotechnol. Agron. Soc. 20:3-12.

Luo, M. F., P. J. Boettcher, L. R. Schaeffer, and J. C. Dekkers. 2001. Bayesian inference for categorical traits with an application to variance component estimation. J. Dairy Sci. 84:694-704.

Madsen, P., and J. Jensen. 2013. A User's Guide to DMU. A Package for Analysing Multivariate Mixed Models. Version 6, release 5.2 http://dmu.agrsci.dk/DMU/.

Negussie, E., I. Stranden, and E. A. Maentysaari. 2008. Genetic association of clinical mastitis with test-day somatic cell score and milk yield during first lactation of Finnish Ayrshire cows. J. Dairy Sci. 91:1189-1197.
Nyman, A. K., T. Ekman, U. Emanuelson, A. H. Gustafsson, K. Holtenius, K. P. Waller, and C. H. Sandgren. 2007. Risk factors associated with the incidence of veterinary-treated clinical mastitis in Swedish dairy herds with a high milk yield and a low prevalence of subclinical mastitis. Prev. Vet. Med. 78:142-160.

Oviedo-Boyso, J., J. J. Valdez-Alarcon, M. Cajero-Juarez, A. OchoaZarzosa, J. E. Lopez-Meza, A. Bravo-Patino, and V. M. Baizabal-Aguirre. 2007. Innate immune response of bovine mammary gland to pathogenic bacteria responsible for mastitis. J. Infect. 54:399-409.

Pantoja, J. C. F., C. Hulland, and P. L. Ruegg. 2009. Somatic cell count status across the dry period as a risk factor for the development of clinical mastitis in the subsequent lactation. J. Dairy Sci. 92:139-148

Powers, D. A., and Y. Xie. 2000. Statistical Methods for Categorical Data Analysis. Vol. 106. Academic Press, New York, NY.

R Core Team. 2016. R: A language and environment for statistical computing. R Foundation for Statistical Computing, Vienna, Austria. https://www.r-project.org/.

Sargeant, J. M., H. M. Scott, K. M. Leslie, M. J. Ireland, and A. Bashiri. 1998. Clinical mastitis in dairy cattle in Ontario: Frequency of occurrence and bacteriological isolates. Can. Vet. J. 39:33-38.

Sato, K., P. C. Bartlett, L. Alban, J. F. Agger, and H. Houe. 2008. Managerial and environmental determinants of clinical mastitis in Danish dairy herds. Acta Vet. Scand. 50:4. https://doi. org/10.1186/1751-0147-50-4.

Schukken, Y. H., D. Bar, J. Hertl, and Y. T. Grohn. 2010. Correlated time to event data Modeling repeated clinical mastitis data from dairy cattle in New York State. Prev. Vet. Med. 97:150-156.

Shook, G. E., and M. M. Schutz. 1994. Selection on somatic cell score to improve resistance to mastitis in the United States. J. Dairy Sci. 77:648-658.

Smith, B. J. 2007. boa: An R package for MCMC output convergence assessment and posterior inference. J. Stat. Softw. 21:1-37.

Sordillo, L. M., and K. L. Streicher. 2002. Mammary gland immunity and mastitis susceptibility. J. Mammary Gland Biol. Neoplasia $7: 135-146$

Sørensen, L. P., M. Bjerring, and P. Løvendahl. 2016. Monitoring individual cow udder health in automated milking systems using online somatic cell counts. J. Dairy Sci. 99:608-620.

Sørensen, L. P., T. Mark, P. Madsen, and M. S. Lund. 2009. Genetic correlations between pathogen-specific mastitis and somatic cell count in Danish Holsteins. J. Dairy Sci. 92:3457-3471.

Steeneveld, W., H. Hogeveen, H. W. Barkema, J. van den Broek, and R. B. M. Huirne. 2008. The influence of cow factors on the incidence of clinical mastitis in dairy cows. J. Dairy Sci. 91:1391-1402.

Sun, C., P. Madsen, U. S. Nielsen, Y. Zhang, M. S. Lund, and G. Su. 2009. Comparison between a sire model and an animal model for genetic evaluation of fertility traits in Danish Holstein population. J. Dairy Sci. 92:4063-4071.

Urioste, J. I., J. Franzén, J. J. Windig, and E. Strandberg. 2012 Genetic relationships among mastitis and alternative somatic cell count traits in the first 3 lactations of Swedish Holsteins. J. Dairy Sci. 95:3428-3434.

van den Borne, B. H. P., J. C. M. Vernooij, A. M. Lupindu, G. van Schaik, K. Frankena, T. J. G. M. Lam, and M. Nielen. 2011. Relationship between somatic cell count status and subsequent clinical mastitis in Dutch dairy cows. Prev. Vet. Med. 102:265-273.

Vazquez, A. I., D. Gianola, D. Bates, K. A. Weigel, and B. Heringstad. 2009. Assessment of Poisson, logit, and linear models for genetic analysis of clinical mastitis in Norwegian Red cows. J. Dairy Sci 92:739-748.

Vazquez, A. I., M. A. Perez-Cabal, B. Heringstad, M. Rodrigues-Motta, G. J. M. Rosa, D. Gianola, and K. A. Weigel. 2012. Predictive ability of alternative models for genetic analysis of clinical mastitis. J. Anim. Breed. Genet. 129:120-128.

Wang, C. S. 1998. Implementation issues in Bayesian analysis in animal breeding. Pages 481-488 in Proc. 6th World Congr. Genet. Appl. Livest. Prod. University of New England, Armidale, Australia. 
Welderufael, B. G., D. J. de Koning, L. L. G. Janss, J. Franzén, and W. F. Fikse. 2017. Simultaneous genetic evaluation of simulated mastitis susceptibility and recovery ability using a bivariate threshold sire model. Acta Agric. Scand. A Anim. Sci. https://doi. org/10.1080/09064702.2016.1275761.

Wilmink, J. 1987. Adjustment of test-day milk, fat and protein yields for age, season and stage of lactation. Livest. Prod. Sci. 16:335348.

Wolf, J., M. Wolfova, and M. Stipkova. 2010. A model for the genetic evaluation of number of clinical mastitis cases per lactation in Czech Holstein cows. J. Dairy Sci. 93:1193-1204.
Yazdi, M. H., P. M. Visscher, V. Ducrocq, and R. Thompson. 2002. Heritability, reliability of genetic evaluations and response to selection in proportional hazard models. J. Dairy Sci. 85:1563-1577.

Yin, T., B. Bapst, U. U. von Borster, H. Simianer, and S. Konig. 2014. Genetic analyses of binary longitudinal health data in small low input dairy cattle herds using generalized linear mixed models. Livest. Sci. 162:31-41.

\section{APPENDIX}

The random effects were assumed to be normally distributed with zero means and (co)variance structure in a matrix notation.

For the sire model,

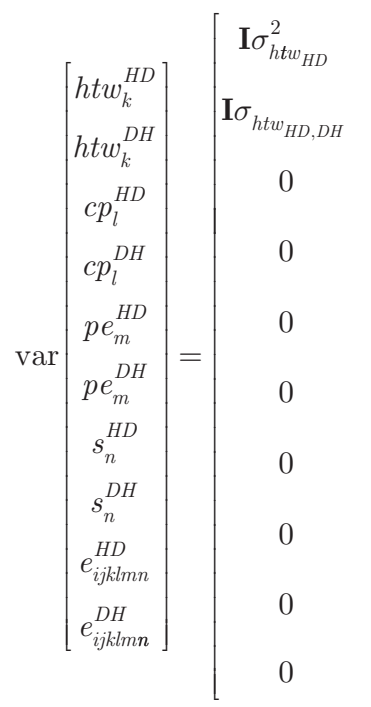

$\mathbf{I} \sigma_{h t w_{H D, D H}}$
$\mathbf{I} \sigma_{h t w_{D H}}^{2}$
0
0
0
0
0
0
0
0

$\begin{array}{cc}0 & 0 \\ 0 & 0 \\ \mathbf{I} \sigma_{c p_{H D}}^{2} & \mathbf{I} \sigma_{c p_{H D, D H}} \\ \mathbf{I} \sigma_{c p_{H D, D H}} & \mathbf{I} \sigma_{c p_{D H}}^{2} \\ 0 & 0 \\ 0 & 0 \\ 0 & 0 \\ 0 & 0 \\ 0 & 0 \\ 0 & 0\end{array}$

0
0
0
0
$\mathbf{I} \sigma_{p e_{H D}}^{2}$
$\mathbf{I} \sigma_{p e_{D H, H D}}$
0
0
0
0

0
0
0
0
$\mathbf{I} \sigma_{p e_{H D, D H}}$
$\mathbf{I} \sigma_{p e_{D H}}^{2}$
0
0
0
0

0
0
0
0
0
0
$\mathbf{A} \sigma_{s_{H D}}^{2}$
$\mathbf{A} \sigma_{s_{D H, H D}}$
0
0

0
0
0
0
0
0
$\mathbf{A} \sigma_{s_{H D, D H}}$
$\mathbf{A} \sigma_{s_{D H}}^{2}$
0
0

$\left.\begin{array}{cc}0 & 0 \\ 0 & 0 \\ 0 & 0 \\ 0 & 0 \\ 0 & 0 \\ 0 & 0 \\ 0 & 0 \\ 0 & 0 \\ \mathbf{I} \sigma_{e_{H D}}^{2} & 0 \\ 0 & \mathbf{I} \sigma_{e_{D H}}^{2}\end{array}\right]$

For the animal model,

$$
\operatorname{var}\left[\begin{array}{c}
h t w_{k}^{H D} \\
h t w_{k}^{D H} \\
c p_{l}^{H D} \\
c p_{l}^{D H} \\
p e_{m}^{H D} \\
p e_{m}^{D H} \\
a_{m}^{H D} \\
a_{m}^{D H} \\
e_{i j k l m}^{H D} \\
e_{i j k l m}^{D H}
\end{array}\right]=\left[\begin{array}{cccccccccc}
\mathbf{I} \sigma_{h t w_{H D}}^{2} & \mathbf{I} \sigma_{h t w_{H D, D H}} & 0 & 0 & 0 & 0 & 0 & 0 & 0 & 0 \\
\mathbf{I} \sigma_{h t w_{H D, D H}} & \mathbf{I} \sigma_{h t w_{D H}}^{2} & 0 & 0 & 0 & 0 & 0 & 0 & 0 & 0 \\
0 & 0 & \mathbf{I} \sigma_{c p_{H D}}^{2} & \mathbf{I} \sigma_{c p_{H D, D H}} & 0 & 0 & 0 & 0 & 0 & 0 \\
0 & 0 & \mathbf{I} \sigma_{c p_{H D, D H}} & \mathbf{I} \sigma_{c p_{D H}}^{2} & 0 & 0 & 0 & 0 & 0 & 0 \\
0 & 0 & 0 & 0 & \mathbf{I} \sigma_{p e_{H D}}^{2} & \mathbf{I} \sigma_{p e_{H D, D H}} & 0 & 0 & 0 & 0 \\
0 & 0 & 0 & 0 & \mathbf{I} \sigma_{p e_{D H, H D}} & \mathbf{I} \sigma_{p e_{D H}}^{2} & 0 & 0 & 0 & 0 \\
0 & 0 & 0 & 0 & 0 & 0 & \mathbf{A} \sigma_{a_{H D}}^{2} & \mathbf{A} \sigma_{a_{H D, D H}} & 0 & 0 \\
0 & 0 & 0 & 0 & 0 & 0 & \mathbf{A} \sigma_{a_{D H, H D}} & \mathbf{A} \sigma_{a_{D H}}^{2} & 0 & 0 \\
0 & 0 & 0 & 0 & 0 & 0 & 0 & 0 & \mathbf{I} \sigma_{e_{H D}}^{2} & 0 \\
0 & 0 & 0 & 0 & 0 & 0 & 0 & 0 & 0 & \mathbf{I} \sigma_{e_{D H}}^{2}
\end{array}\right]
$$


where $\mathbf{I}$ are identity matrices of appropriate size, and $\mathbf{A}$ is the additive genetic relationship matrix. The $\sigma_{h t w_{H D}}^{2}$, $\sigma_{c p_{H D}}^{2}, \sigma_{p e_{H D}}^{2}, \sigma_{s_{H D}}^{2}$, or $\sigma_{a_{H D}}^{2}$, and $\sigma_{e_{H D}}^{2}$ terms were variances for herd-test-week, cow-parity interaction, cow permanent environmental, sire or animal additive genetic, and residual effects, respectively, for HD. Similarly, the $\sigma_{h t w_{D H}}^{2}, \sigma_{c p_{D H}}^{2}, \sigma_{p e_{D H}}^{2}, \sigma_{s_{D H}}^{2}$, or $\sigma_{a_{D H}}^{2}$, and $\sigma_{e_{D H}}^{2}$ were variances for herd-test-week, cow-parity interaction, cow permanent environmental effect, sire or animal additive genetic, and residual effects, respectively, for DH. The $\sigma_{p e} e_{H, D H}$ and $\sigma_{s_{H D, D H}}$ or $\sigma_{a_{H D, D H}}$ were cow permanent environmental and sire or animal additive covariance between HD and DH. The residual variance $\left(\sigma_{e}^{2}\right)$ is not identifiable, and it was fixed to 1 . Other terms are as defined following equation [3]. The residual covariance between the traits was also constrained to 0 because the 2 transitions are by nature not observed at the same moment. Relationships among individuals were considered in both the sire and animal threshold models. For all the 1,791 cows and 107 sires in our data file, a pedigree file was built and traced back to a maximum of 10.95 and an average of 4.64 known generations. The pedigree file contained 16,490 animals. 